Brit. Heart $\mathcal{F . , ~ 1 9 6 7 , ~ 2 9 , ~} 417$.

\title{
Movement of Mitral Valve Cusps in Relation to First Heart Sound and Opening Snap in Patients with Mitral Stenosis ${ }^{\star}$
}

\author{
BENJAMIN W. McCALL† AND JOHN L. PRICE \\ From the Department of Cardiology and Radiology, St. George's Hospital, London, and the Department of Medicine, \\ Duke University Medical Center, Durham, North Carolina, U.S.A.
}

Doubt has been cast upon the valvular origin of the first heart sound since the finding of a delay between the cross-over of the ventricular and atrial pressure tracings and the sound attributed to closing of the corresponding atrio-ventricular valve. There is a similar delay after the left ventricular pressure falls below that in the left atrium before the occurrence of the opening snap in mitral stenosis. During the routine investigation of patients with mitral stenosis the movements of the mitral valve have been recorded by selective cine-angiocardiography simultaneously with the heart sounds.

\section{METHOD}

A record of the cine frames and high frequency sound recordings from the mitral area and lower left sternal edge were obtained simultaneously on an English Cambridge multichannel phonocardiograph at a paper speed of $100 \mathrm{~mm}$. per second. The simultaneous high frequency recordings from the two areas allowed identification of the high frequency, high energy component of the first sound maximal at the mitral area and attributed to mitral closure. Because of the presence of mitral stenosis, this component was later than the high frequency component of the first sound maximal at the lower left sternal edge and attributed to tricuspid closure. This technique (Leatham, 1952, 1954) also permitted accurate identification of the opening snap from the aortic and pulmonary components of the second sound.

Each of the 10 patients in this study had mitral stenosis, a loud mitral component of the first heart sound,

Received June 22, 1966.

* This study was supported in part by a grant-in-aid from the North Carolina Heart Association and by a post-doctoral training grant (N.I.H.) from the National Heart Institute, Public Health Service.

† Present address: Baylor Medical School, Houston, Texas, U.S.A.

$\ddagger$ Present address: Milford Chest Hospital, Surrey. and an opening snap of the mitral valve. No patient had appreciable mitral regurgitation and none had a third heart sound. Four patients had mild aortic regurgitation. Six were in sinus rhythm and four had atrial fibrillation at the time of the investigation.

Right heart catheterization was performed following a cut-down on the saphenous vein or percutaneous introduction of a catheter into the femoral vein. This was followed by left atrial catheterization using the transseptal approach (Brockenbrough and Braunwald, 1960). The tip of the catheter was placed so that it lay freely in the left atrium above the mitral valve. Retrograde catheterization of the left ventricle was performed percutaneously from the femoral artery in three patients. Left atrial pressures, left ventricular pressures, lead II of the electrocardiogram, and a high frequency external phonocardiogram were recorded simultaneously with the patient in the supine position. The patient was then rotated 60 degrees into the right anterior oblique position, and a cine-angiocardiogram, with simultaneous electrocardiogram and phonocardiogram, was recorded during held inspiration.

The left atrial injection of $20-25 \mathrm{ml}$. Urografin 76 was made with a pressure injector at $80 \mathrm{lb}$. per sq. in.

The cine-angiocardiograms were taken from a 5 -inch image intensifier using a $35 \mathrm{~mm}$. cine camera at 44 frames per second, or a 9-inch image intensifier using a $16 \mathrm{~mm}$. cine camera with a lens for overframing at 32 frames per second. Double X film was used in both cameras. In the 5-inch image intensifier the cine camera initiated each $x$-ray exposure $(0.005 \mathrm{sec}$. in duration) with a high speed relay which in turn energized an event marker on the photographic recorder. In the 9-inch image intensifier, a high speed photoelectric cell initiated an impulse each time the lens of the cine camera was opened. The delay in both of these systems was less than $0.0025 \mathrm{sec}$. These impulses, which indicated the exposure of each cine frame, were recorded simultaneously with the electrocardiogram and a high frequency external phonocardiogram during the cine-angiocardiogram. 

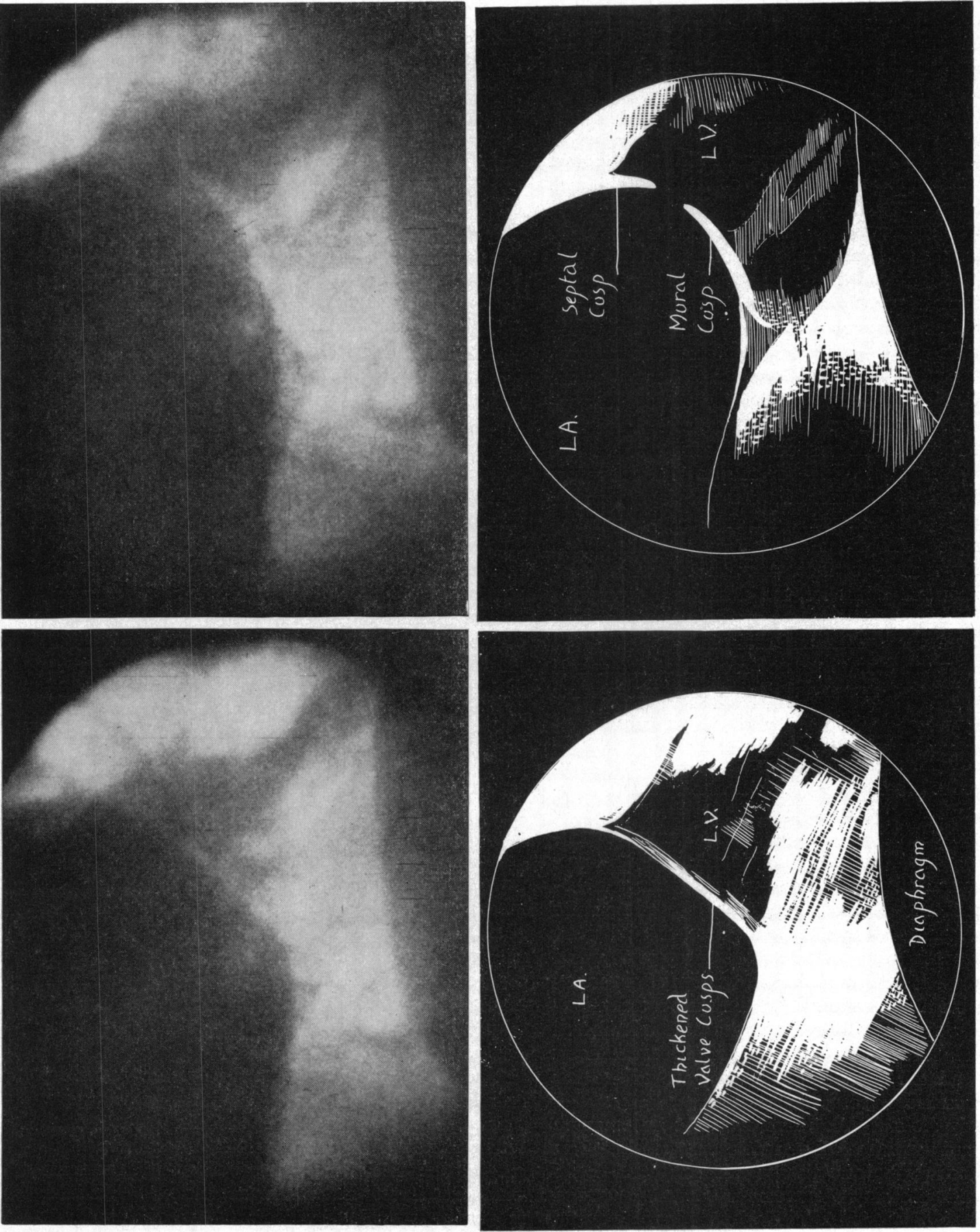

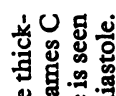
暨 出 1

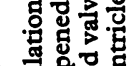

A 弗哭 昰密 원용 $\leadsto$ 两

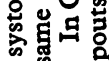
.5 0

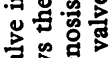
宩密 通 列 응 동면 ๙

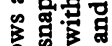
要

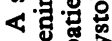
咩 范 点吉高. 웜음 过定 政 足 ส] 형형 的突

总焉密 क क 今ै कौ 욜

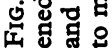


Each cine-angiocardiogram was then analysed and mitral valve movement was correlated with the opening snap of the mitral valve, the supposed mitral component of the first heart sound, the left atrial pressure pulse (not recorded simultaneously with the cine), the left ventricular pressure pulse, and the electrocardiogram.

\section{RESULTS}

In each cine-angiocardiogram at least some part of the thickened mitral valve could be visualized. Two distinct types of valve were observed. In one, there was a continuous dome-shaped halo extending from the septal to the mural portion of the annulus, but the cusps could not be visualized separately. This dome moved like a diaphragm and in diastole appeared as a convex protrusion into the left ventricle. In systole it was partially flattened but maintained its curve toward the ventricle. In the second type of valve, the mural and often the septal portions of the cusps could be visualized separately. In systole the distal portion protruded into the left atrium giving the centre of the valve a convexity toward the left atrium. In diastole angulation of the cusps persisted until the final rapid opening movement when the distal cusp margins extended further toward the ventricular walls and either broke the symmetrical line of the dome or assumed a conical shape. The Figure shows an example of each type of valve in systole and diastole.

There were four phases of motion of the mitral valve cusps and annulus during a complete cardiac cycle. In early systole, $0.03-0.04 \mathrm{sec}$. after the $Q$ wave of the electrocardiogram, there was a sudden ascent of the mitral valve toward the left atrium. This ascent began at the time when the left ventricular pressure pulse crossed the left atrial pressure pulse and continued for one or two frames $(0.023$ $0.046 \mathrm{sec}$.). The mitral component of the first heart sound occurred at the instant when the upward movement of the valve into the left atrium stopped. After the valve had closed there was no subsequent movement until late in systole, when there was a descent of the mural portion of the annulus toward the left ventricle. This movement continued over two to three frames and terminated before the aortic component $\left(A_{2}\right)$ of the second heart sound and the peak of the "V" wave of the left atrial pressure pulse.

Shortly after $A_{2}$ the valve cusps began to move downward into the left ventricle and continued in this direction for one or two frames $(0.023-0.046$ sec.), with the major movement occurring toward the end of this period. The opening snap occurred after the peak of the " $V$ " wave of the left atrial pressure pulse, and coincided with the end of the downward movement of the valve in all patients.
There was little change in position of the valve cusps during the remaining part of the diastole in those with atrial fibrillation. In patients with sinus rhythm atrial contraction usually caused a sudden movement of the valve leaflets toward the ventricle and increased flow of radiopaque material into the left ventricle.

In mid-diastole there was an upward movement of the mural portion of the annulus toward the left atrium. There was no significant movement of the septal portion of the annulus during the entire cardiac cycle.

In every case, a jet of radiopaque material could be seen entering the left ventricle with the first diastole. In some cases, the left ventricle was never completely opacified and a jet could be seen over several cardiac cycles. No flow of contrast material occurred before the opening snap. There was a delay in emptying of the left atrium in all patients.

\section{Discussion}

In mitral stenosis, the thickened cusps of the mitral valve can be visualized and their motion studied by using cine-angiocardiography, following the injection of radiopaque material into the left atrium. The previously reported convex protrusion of the mitral valve into the left ventricle during diastole (Björk and Lodin, 1960) has been confirmed. Our ability to differentiate the separate cusps agrees with the studies of Björk and Lodin (1960) in the lateral projection, but differs from the observations of Ross, Criley, and Morgan (1961) who were unable to accomplish this using cine-angiocardiography, with the patient rotated 45 degrees in the right anterior oblique position. We have found that rotation of the patient 60 degrees into the right anterior oblique position facilitates separation of the septal from the mural cusp. The use of only 20-25 $\mathrm{ml}$. radiopaque material will outline the valve and opacify the atrium without completely obliterating the valve when it protrudes into either the atrium or the ventricle. Injection of radiopaque material into the left ventricle gives a less satisfactory view of the valves than does the method used in this study.

The movement of the mitral valve cusps and the annulus, especially the septal portion, was greatly reduced as compared with the motion of these structures in two patients with constrictive pericarditis but with normal mitral valves and in patients with dominant mitral regurgitation. Valvular movement was further decreased when significant calcification was present.

The mitral valve begins its ascent and is probably functionally closed, as stated by $\mathrm{Di}$ Bartolo and 
associates (1961) and Sarnoff, Gilmore, and Mitchell (1962), when the left ventricular pressure pulse crosses the left atrial pressure pulse. The mitral component of the first heart sound, however, was found to occur later in systole when the rapidly ascending cusps were suddenly stopped by the papillary muscles and chordæ tendineæ.

The opening snap occurred at the instant when the rapid movement of the cusps into the left ventricle suddenly stopped. The fall in left atrial pressure (" $Y$ " descent) before the opening snap has three possible explanations: (1) the descent of the annulus in late systole, (2) flow of blood across the valvular cusps before the opening snap, and (3) the initial downward movement of the valve early in diastole. The observations presented here show that the descent of the annulus in late systole terminated before the beginning of the " $Y$ " descent of the left atrial pressure pulse, and that there was no flow of radiopaque material across the valve cusps before the opening snap. The descent of the cusps of the mitral valve over a period of $0.023-0.046$ second before the opening snap, however, allows a fall in left atrial pressure by enlarging the capacity of the chamber. This explains the beginning of the " $Y$ " descent before the opening snap. This concept agrees with the postulate of Rich (1959).

\section{SUMMARY}

Synchronized recordings of the movements of the cusps and annulus of the mitral valve and of the heart sounds have been made in 10 patients with mitral stenosis. Two types of cusp movement are described. The abrupt cessation of movement of the valve into the left atrium coincided with the mitral component of the first sound, and cessation of movement into the left ventricle coincided with the opening snap. The delay which has been noted between the cross-over positions on atrial and ventricular pressure traces and the occurrence of the first heart sound and the mitral opening snap are explained.

\section{REFERENCES}

Björk, V. O., and Lodin, H. (1960). The evaluation of mitral stenosis with selective left ventricular angiocardiography. f. thorac. cardiovasc. Surg., 40, 17.

Brockenbrough, E. C., and Braunwald, E. (1960). A new technic for left ventricular angiocardiography and transseptal left heart catheterization. Amer. F. Cardiol., 6, 1062.

Di Bartolo, G., Nunez-Dey, D., Muiesan, G., MacCanon, D. M., and Luisada, A. A. (1961). Hemodynamic correlates of the first heart sound. Amer. F. Physiol., 201, 888.

Leatham, A. (1952). Phonocardiography. Brit. med. Bull., $8,333$.

- (1954). Splitting of the first and second heart sounds. Lancet, 2, 607.

Rich, C. B. (1959). The relation of heart sounds to left atrial pressure. Canad. med. Ass. F., 81, 800.

Ross, R. S., Criley, J. M., and Morgan, R. H. (1961). Cineangiocardiography in mitral valve disease. Trans. Ass. Amer. Phycns, 74, 271.

Sarnoff, S. J., Gilmore, J. P., and Mitchell, J. H. (1962). Influence of atrial contraction and relaxation on closure of mitral valve. Observations on effects of autonomic nerve activity. Circulat. Res., 11, 26. 